\title{
Corpo e alteridade como expressão e produção cultural: Um olhar empírico
}

\section{Body and otherness as expression and cultural production: An empirical look}

\author{
António Camilo Cunha \\ Universidade do Minho
}

\begin{abstract}
Resumo
A cultura e o corpo estão intrinsecamente ligados, tendo um carater dinâmico de Ser e de se Compreender. Desenvolvem-se e complementam-se entre si, permanentemente, tendo sempre na sua dinâmica relacional um suporte de carater histórico e até filosófico. Se para Descartes (1596-1650), o corpo era um instrumento (res-extensa) do cogito (res- cogito), na atualidade o corpo e cogito fazem o "eu". Um "eu" à maneira de Espinosa (1632-1677), isto é, um "eu" monista, onde corpo, alma, espírito - são uma totalidade. Um corpo que na sua totalidade emerge como expressão e produção cultural, não esquecendo a relação com outros "eus"..

Palavras-Chave: Cultura, corpo, culturas, alteridade, sociedades.
\end{abstract}

\begin{abstract}
Culture and the body are intrinsically linked, having a dynamic character of Being and Understanding. They develop and complement each other, permanently, always having in their relational dynamics a support of a historical and even philosophical character. If, for Descartes (1596-1650), the body was an instrument (res-extensive) of the cogito, the body and cogito now make the "I". A "I" in the manner of Spinoza (1632-1677), that is, a monistic "I", where body, soul, spirit - are a totality. A body that in its entirety emerges as an expression and cultural production, not forgetting the relationship with other "I's" Keywords: Culture, body, cultures, otherness, societies.
\end{abstract}

Podemos dizer com algum acerto que tudo o que nos rodeia é "cultura" e "natureza" e que o corpo faz parte integrante desses envolvimentos. Corpo, cultura, natureza estão interligados entre si numa dinâmica expressiva e "evolutiva" deixando ficar os seus registos e marcas no processo histórico. (Kroeber, 1993). Foi a propósito desta temática (relação) que fizemos um pequeno estudo exploratório sobre a relação cultura/corpo, por forma a tentar compreender-se melhor a relação que existe entre essas duas representações/realidades - neste tempo pós-moderno.

Neste sentido o texto que apresentamos percorre dois caminhos: i) o caminho onde fizemos uma pequena consulta teórica sobre os termos em análise; ii) o caminho do campo investigativo - questionando diversos pessoas/alunos sobre a problemática em análise. Neste contexto criamos uma pequena tertúlia com os nossos alunos (alunos do Mestrado em Educação Física e Lazer) à volta de uma mesa, em que cada um deu/disse a sua representação (conhecimento/experiência/vivências) sobre os dois conceitos em reflexão - corpo e cultura. Daqui resultaram respostas e conclusões muito interessantes do ponto de vista reflexivo e interpretativo.

\section{Sobre Cultura.}

Existem muitas definições de cultura. Numa definição simples, cultura será um conjunto de ideias, valores, normas e comportamentos, materiais que a sociedade cria, constrói e transmite no presente e de geração em geração "permitindo" um maior enriquecimento da mesma. Alves (2004) vai referir que existem várias manifestações de cultura: a religião, a politica, a economia, a tecnologia, a ciência, o saber académico, a literatura, a arte, (o desporto - grifo nosso), são expressões culturais ... e que todas elas deviam caminhar para o sentido do bem, da verdade, da beleza, da justiça, entre outros, valores.

Outras definições de cultura podem ser encontradas e que apresentam caraterísticas muito iguais. Para o antropólogo Tylor (1871, cit por Alves, 2004), por exemplo vai dizer que cultura, é um complexo que inclui conhecimento, crenças, arte, valores, leis, costumes e outras aptidões e hábitos adquiridos pelo homem como membro da sociedade. Para outro Antropólogo, Linton (1945, cit, por Alves, 2004) vai definir cultura como sendo, a configuração de comportamento aprendido $e$ resultados de comportamentos cujos elementos componentes são partilhados e transmitidos pelos membros de uma sociedade particular" (p. 9).

Já Leite (2005), quando relaciona cultura/corpo/arte como estruturantes da educação e da identidade. A criança muito pequena não é um "ser" mas um "há-de ser", que tem de ser "chamado à existência". Esse aspecto do ser, viver é convocado na cultura, dito que os seus elos de ligação vão permitir que a criança se transforme no "ser" - "ser" cultural, "ser" social, "ser" pessoa.

Outra dimensão do presente que tem tido uma influência inquestionável na produção e transmissão de cultura, diz respeito à técnica e tecnologia. A informação circula através das novas tecnologias da comunicação e da informação, proporcionando uma troca cultural nunca antes vista. Os media encurtam as distâncias, a técnica faz viajar a grandes distâncias num curto espaço de 
tempo, proporcionando um deslocamento/diálogo de culturas que cria e recria rápidas mudanças sociais.

Estamos num tempo de expansão das relações humanas, do tempo e do espaço que diz o local e o global nas suas objetividades e subjetividades.

Por outro lado a tecnologia permite uma coexistência global (homogeneização cultural) e ao mesmo tempo uma visibilidade da diversidade cultural. (Daólio, 1995; Sommer \& Bujes, 2006; Geertz, 1989).). Neste sentido talvez possamos dizer que a cultura global precisa da diferença para prosperar criando novas identificações/identidades globais e locais, resultantes da partilha de conhecimento.

\section{Sobre o Corpo.}

O corpo tem sido visto, observado, refletido, estudado, ao longo dos tempos sob a perspetiva do pensamento filosófico e depois das várias ciências - quer sejam as ciências físicas quer sejam as ciências humanas. Por outro lado o corpo sempre foi alvo (objeto e sujeito) de reflexão, ao longo dos tempos por outros atores - artistas, escritores e pensadores que representaram e retrataram a imagem do corpo e o corpo em diferentes dimensões: orgânica, educativa, simbólica, cultural.

Do ponto de vista antropológico, por exemplo, nas etapas de evolução do homem, constata-se as transformações que o corpo foi sofrendo devido às adaptações ao meio a que foi sujeito e as adaptações que teve de adoptar para a sua sobrevivência, ao longo de milhares de anos. Estas transformações do corpo estiveram sempre associadas às evoluções e transformações da estrutura do nosso crânio (cérebro) e aos movimentos/pensamentos advindos daí. Essa mudança também é verificável do ponto de vista micro (ontológico/genético) - desde que nascemos, o corpo vai sofrendo alterações de maturação e crescimento, de acordo com o desenvolvimento psíco - sócio - motor. Por outro lado, não podemos esquecer as regiões do planeta, que juntamente com as dimensões culturais (politica, ideologia, religião...) fazem, mostram e "constroem" diferentes corpos.

Também a corrente mais filosófica e existencial olharam para a dimensão corpo. Por exemplo, Merleau-Ponty (1994), vai dizer que o corpo não é um objecto a ser treinado, mas um ser que nos ensina, que nos faz ser - o que somos. O corpo e a consciência de si não se podem dissociar. O corpo está fixado nos seus contornos, abrindo-se através da pele para percepcionar o mundo e envolver-se nele, transmitindo o feedback à consciência/cérebro que o comanda e o faz agir. $\mathrm{O}$ corpo vai crescendo de acordo com as experiências que o cérebro vai vivenciando. $\mathrm{O}$ corpo é o mais belo traço da memória da vida desde o nascimento até à morte. O ser humano é o corpo, o corpo que tem, que é o Seu...e que diz quem o é, quem o tem!

\section{Cultura e Corpo.}

No tocante à relação cultura/corpo, Moreira (2008) refere que o corpo corporiza uma cultura. Na mesma linha Silveira \& Camilo Cunha (2014) afirmam que o corpo e cultura caminham de mãos dadas. O corpo expressa não só uma cultura, como também faz cultura - faz acrescentos. Toda a história é protagonizada por características físicas (psicológicas, sociais...) de um corpo (humano). Por exemplo, na arte - numa imagem revela-se a época a que remonta a sua aparência física (adereços, estilos de vestir, de pentear, etc.).

Ser pessoa é ter um corpo culturalmente construído como temos vindo a referir - onde a imagem do homem e da mulher têm vindo a ser constantemente concebidas e (re) elaboradas ao longo dos tempos históricos pelas sociedades e culturas em que habitam. O corpo é, mais do que nunca, um "instrumento" do $e u$ - pessoal e individual que comunica com os outros e com o mundo. Ou melhor, o corpo é, mais do que nunca, um " $\mathrm{eu}$ ” (total) que está para lá da ideia de instrumento.

Nas sociedades ocidentais o corpo mostra as marcas da história e da cultura nomeadamente o sentido da libertação dos grilhões culturais, ideológicos e morais/religiosos. Por exemplo, Barbosa (2003) refere que nos estados católicos, o corpo foi pecador e como tal tinha de ser "torturado pela culpa" até à morte. Ao denegrir o corpo, estava-se a denegrir a alma e as ideias. $\mathrm{Na}$ era pós-moral (Iluminismo) esse imperativo passa a ser visto como uma perspetiva de desejo de higiene (dimensão médica) com a defesa da preservação e tratar o do corpo. O olhar para o corpo como algo a proteger (para além das questões de saúde), passa também a ter uma dimensão estética - objeto/sujeito de sedução. A partir dos anos 70 (sec. XX) o corpo começaria a estar noutro patamar ao ser tratado como um "bem de consumo" fazendo parte da indústria económica e cultural. A aparência corporal começa a fazer parte dos padrões das sociedades modernas ocidentais, obcecadas agora, pela forma - a estrutura. Opta-se por cirurgias estéticas, alimentos dietéticos, sistemas anti-envelhecimento, produtos light e diet para que o corpo se torne perfeito à luz das transformações dos ditames económicos e estéticos. "É o culto do corpo e da estética corporal, no triplo paradigma actual da beleza, saúde e juventude." (Barbosa, 2003, p.108). Muitas vezes nem chegamos a questionar os direitos, limitações, necessidades, exigências, desejos e potencialidades do corpo. O que interessa é a satisfação pessoal como resposta aos padrões e à norma da sociedade de consumo.

Assim, a cultura do corpo, hoje, é amplamente valorizada, destacando-se como como uma cultura transversal. O corpo é visto como um símbolo de valores e de culturas que circulam a uma velocidade estonteante. Os media (como já referimos) fazem com que esta transmissão de culturas seja excessivamente rápida, provocando-nos uma desorientação tal, que o mesmo precisa reencontrar-se, reencontrar o corpo para se sentir seguro, para sentir o "eu". O corpo como meio, como refere (Garcia, 1997) está também ao serviço de algo: como o lazer, o trabalho, as atividades sociais, transmitindo desta forma a cultura. O corpo é o símbolo cultural construído, e reconstruído diariamente. O corpo expressa e faz cultura (Silveira \& Camilo Cunha, 2014), corporiza uma cultura (Moreira, 2008). Corpo e cultura caminham, então, de mãos dadas. $\mathrm{O}$ corpo humano traz consigo uma cultura que revela, como se formou, como vive e como se transforma. O corpo constitui-se como objeto de cuidados, atenções e investimentos 
quotidianos, sob a forma de saúde, beleza, sedução, força, entre outras "marcas" de distração.

Estas realidades trazem outros acrescentos á ideia de imagem corporal valorizando a sua exterioridade. Tudo que é exterior e superficial tem hoje em dia uma enorme importância que se contrapõe a valores interiores. $\mathrm{O}$ corpo passa a ser um objecto de consumo e de transformação, à medida de cada um. Fazem-se grandes investimentos para se afirmar socialmente e não cair no esquecimento. Na sociedade do séc. XXI, predomina o parecer sobre o ser. Esta é a cultura do nosso tempo. Ter um corpo belo é sinónimo de qualidade de vida. Há uma obsessão em manter um corpo jovem que a sociedade definiu como norma. As sugestões de como cuidar o corpo, desde cuidados higiénicos, cremes hidratantes e tipo de exercícios para ter e manter um "corpo perfeito", continuam agora num estádio quase radical.

Outro aspeto interessante é a ideia do corpo como locus de marcas escritas - aspeto ancestral (tribos...).Esta ideia de escrever o (no) corpo, perfurá-lo, adorná-lo com os mais estranhos adereços e tatuagens é (uma) outra forma de expressão cultural.

Centrando-nos agora um pouco para a área que nos anima de forma particular - o desporto - vamos também constatar que existem determinados corpos característicos de determinadas modalidades. Cada desporto exige determinados exercícios para desenvolver as capacidades específicas de cada um, com o objectivo de atingir os melhores resultados. Estes corpos atléticos, na sociedade actual, são utilizados na publicidade como forma de promover esta imagem corporal, do tempo que passa. Para vender vários produtos, utilizando-se a imagem de corpos esculturais, fomentando sempre, a ideia de que todas as pessoas poderão ter um corpo perfeito. No entanto, e muitas vezes, esquecemos que outras coisas se escondem. Estamos a falar de produtos/substâncias altamente neurotóxicas e até fatais. Por outro lado, não podemos esquecer o potencial de alteridade que o desporto tem e manifesta. O "outro" é fundamental para a construção do "eu", ou se quisermos para a construção do meu corpo. O "outro" como uma variável cultural que me faz e que eu o faço - a ela. Uma dialética de influência.

Em termos de síntese, talvez possamos dizer que corpo é um bem material e espiritual. É capaz de ser e mostrar cultura e ao mesmo tempo (re) construir cultura.

\section{O caminho metodológico}

As questões sobre o termo "cultura" e "corpo" foram colocadas numa aula de Antropologia Cultural - Do Mestrado em Educação Física e Lazer (IEC da Universidade do Minho). Apenas duas questões foram colocadas: O que é a cultura?; O que é o corpo?; e nesse sentido conhecer também as possíveis relações entre corpo e cultura. A partir destas duas questões, estabeleceu-se um debate, uma tertúlia (entrevista em grupo, aberta, interativa - entrevista gravada) sobre o tema, da qual resultaram respostas diferentes $\mathrm{e}$ complementares. Num primeiro momento, as respostas/representações (análise de conteúdo) parecem simples, no entanto, elas apresentaram-se complexas, variadas, múltiplas.

\section{Resultados}

Sobre a questão: O que é a cultura?. Apresentamos alguns registos:

- "A cultura representa a importância da progressão que deve existir na nossa vida. Uma pessoa culta está sempre disposta a aprender, a alargar horizontes, é uma pessoa interessada. Cultura compõe-se também, de hábitos, ideias de um país, costumes e das suas rotinas. Cultura é diversidade, espontaneidade e imaginação";

-“Cultura é o nosso património, o reconhecimento de um artista" ;

-“Cultura é tudo aquilo que caracteriza uma determinada região, desde o que comemos até ao que vestimos. Há diferentes tipos de cultura, oriental e ocidental";

-"Cultura é tudo o que nos rodeia, museus, cinema, biblioteca, teatro e o espaço exterior" ;

"Cultura é o conhecimento adquirido por alguém; uma pessoa culta é uma pessoa que sabe muitas coisas, sobre vários temas. É também a cultura de um povo";

"Cultura tem a ver com a aprendizagem de cada um, é saber o que se passa à nossa volta";

-“A cultura é religião, os costumes e tradições de um local";

“-A cultura pode ter vários significados. Pode ser a cultura de uma terra, estilo de vida das pessoas, as festas e os pratos tradicionais";

-“ Cultura tem a ver com os costumes da cada país na educação, na língua, nas tradições que caracterizam a cultura local";

-“Cultura é o conhecimento que cada um de nós tem, há a cultura de cada país (língua, rituais e tradições)";

-“A cultura é a informação que cada pessoa adquire com o tempo. Pode ser a nível social, económico, politico, etc... Uma pessoa pode enriquecer a sua cultura no dia a dia, através dos livros, jornais, revistas, documentários e experiências de vida";

- “Cultura é o conhecimento que as pessoas têm sobre as coisas. É tudo o que vivenciamos, e nem sempre o mais culto é aquele que possui grande sabedoria porque se não a souber transmitir não tem qualquer benefício para a sociedade. É a modificação, para melhor, de algo, são os hábitos e costumes de um povo. É um conjunto de conhecimentos não muito aprofundados sobre os vários campos do conhecimento humano, sobre a arte, a ciência, a política e a economia. É experiência de Vida";

-“A cultura é a evolução antropológica de uma pessoa num determinado meio, tem a ver com a evolução cultural do seu meio, é o produto da evolução e conhecimento que acumulou. As culturas não desaparecem, transmitem-se de geração em geração";

-“Cultura é o processo de manifestação de valores, ideias, conceitos e saberes que utilizam a criatividade, para explorar e reproduzir os pensamentos, os desejos, formas de estar de uma entidade que se protege num determinado tempo e espaço social e económico. Essa entidade pode ser um grupo com determinadas tendências de interferência social, pode ser uma 
sociedade que vai perpetuar os seus saberes ao longo do tempo, pode ser, também, um grupo de individualidades que perpetuaram os seus saberes no tempo";

-“Cultura é aquilo que fica depois de se esquecer tudo o que se aprendeu";

"Cultura é saber";

-"É conhecimento, arte, música, a cultura gera sentimentos, interesses.";

-"A cultura reflete-se no nosso saber ser e saber estar."

Sobre a questão: O que é o corpo? -"Corpo", simplesmente. Tudo se pode associar. O físico, a personalidade, a mente... Fisicamente, por vezes, o corpo é o estado da alma, para os espiritualmente transparentes. A vontade de ter um corpo esbelto é muito distante de o ter e de o conseguir. A beleza do corpo exterior será o retrato da beleza interior? $\mathrm{O}$ corpo interior não revela aquilo que sente nem tão pouco o que é. É um corpo à parte. É outro "eu". Temos dois corpos o "eu" de interior, e o outro... aquele que mostramos, muito distante do interior. Há uma aproximação entre estes dois corpos entre estes dois "eus" em momentos de cumplicidade, de carência, de amizade verdadeira e de amor";

-“O corpo é aquilo que somos, é a nossa imagem. É a nossa existência, é o nosso próprio ser. Sendo o corpo um ser muito complexo...é orientado pelo cérebro como uma máquina, nasce, vive, movimenta-se e morre";

-“Corpo, no sentido geral e para mim, corresponde à quantidade de massa ocupada por um determinado objecto. Corpo é o conjunto das várias partes que compõem um animal. -“Após a sua morte esse corpo é considerado um cadáver";

-"O corpo é um invólucro que encerra a minha alma";

-“Corpo é o conjunto de órgãos que fazem viver um ser vivo. No caso dos humanos poderemos ter um corpo um pouco mais elaborado";

-"Na minha perspetiva o corpo é um todo, não só na sua constituição anatómica e fisiológica, não só nos seus movimentos delicados como nos violentos."

-"Ao olharmos o corpo vemos um passado que foi delimitando as suas formas, fruto do desgaste da vida; ele é o nosso espelho. Podemos fazer-lhe bem e tê-lo como o queremos, ou mais próximo daquilo que queremos. Fazendo-lhe mal, deixamos de o ter belo ou próximo da beleza (que é hipotética e diferente na perspectiva de cada um). Corpo humano é toda uma estrutura combinada de ossos, músculos, órgãos e pele e que nos mantém na posição vertical";

-"Estrutura fundamental de um "ser" ( ou de um objecto) que ocupa um espaço, que tem uma determinada função. Enfim, é algo que tem existência física (é palpável)";

-"É uma máquina que é comandada por um chipe";

-"É um objecto (matéria) que ocupa espaço";

-“Corpo é o aspecto físico - quantidade de matéria estrutura algébrica algo sólido e visível”;

-"Corpo é a embalagem do que nós realmente somos. Às vezes tem um papel brilhante e um belo laço de cetim, outras, um papel baço, enrugado...sem graça"

\section{Uma análise crítica (grande conclusão)}

Quando analisamos o conteúdo das respostas constatamos que quer a representação de corpo como de cultura, mostram três ideias estruturantes: $i$ ) Um corpo e uma cultura como resultado de uma produção interna humana, espiritual, ético, intelectual com um sentido interior e estético; ii) Um corpo e uma cultura como algo externo - instrumental, mecânico...; iii) Um corpo e uma cultura que estão em interação com o envolvimento local e global e que não esquece a memória, o presente e o futuro.

De alguma forma estamos perante um homem (humanidade) como um ser culturalmente construído, que dá vida ao seu corpo, e à sua cultura ... que dá sentido (s) à vida, na unidade e na diversidade.

A cultura e corpo encontram-se em qualquer lugar, em qualquer homem...

No pedreiro, que conhece a pedra na sua intimidade;

No pastor, que orienta o seu rebanho nos seus afetos;

No médico, que cura o doente na sua humanidade;

No padeiro, que faz o pão na sua felicidade;

$\mathrm{Na}$ mulher, que dá à luz o filho, na sua divindade...

\section{Referencias}

Alves, A. (2004) Comunicação e cultura no processo de socialização. Comunicação apresentada ao II Encontro Luso - Galego de Comunicação e Cultura. Braga: Universidade do Minho. Centro de Estudos de Comunicação e Sociedade.

Barbosa, I. (2003) O Eclodir dos Novos Desportos Como Expressão das Novas Necessidades Sociais. Porto: Universidade do Porto, Faculdade de Ciências do Desporto e Educação Física.

Daolio, J. (1995) Da Cultura do Corpo. Papiros Editores Coleção Corpo Motricidade.

Garcia, R. (1997) Programa e Relatório da Disciplina de Antropologia do Desporto. Porto: Universidade do Porto, Faculdade de Ciências do Desporto e Educação Física.

Geertz, C. (1989). Interpretação das culturas. Rio de Janeiro: Guanabara Koogan,

Leite, V. (2005) Corpo Impregnado pela Arte: Implicações no Campo da Educação.. Agência Financiadora. www.anped.org.br 2009/11/04.

Merleau- Ponty, M. (1994). A fenomenologia da perceção. Tradução de Carlos Alberto Ribeiro de Moura. São Paulo: Martins Fontes.

Moreira, C. (2008). Multiculturalidade e multiculturalismo. In J. C. Rosas (org.) Manual de Filosofia Política (pp. 15-33). Coimbra: Livraria Almedina.

Silveira, L. \& Camilo Cunha, A. (2014). O Jogo e a infância: entre o mundo pensado e o mundo vivido. Santo Tirso: De Facto Editores.

Sommer, L. \& Bujes, M. (2006). Educação e Cultura Contemporânea: Articulações, Provocações e Transgressões em Novas Paisagens. Editora da ULBRA.

Kroeber, A. (1993). Natureza da cultura. Lisboa: Edições 70. 